\begin{tabular}{|c|c|}
\hline 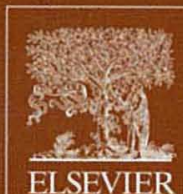 & $\begin{array}{l}\text { HANDBOOK OF EXPLORATION } \\
\text { AND ENVIRONMENTAL GEOCHEMISTRY } 11 \\
\text { M. HALE (SERIES EDITOR) }\end{array}$ \\
\hline
\end{tabular}

\title{
GEOCHEMICAL \\ ANOMALY AND MINERAL PROSPECTIVITY MAPPING IN GIS
}

Emmanuel John M. Garranza

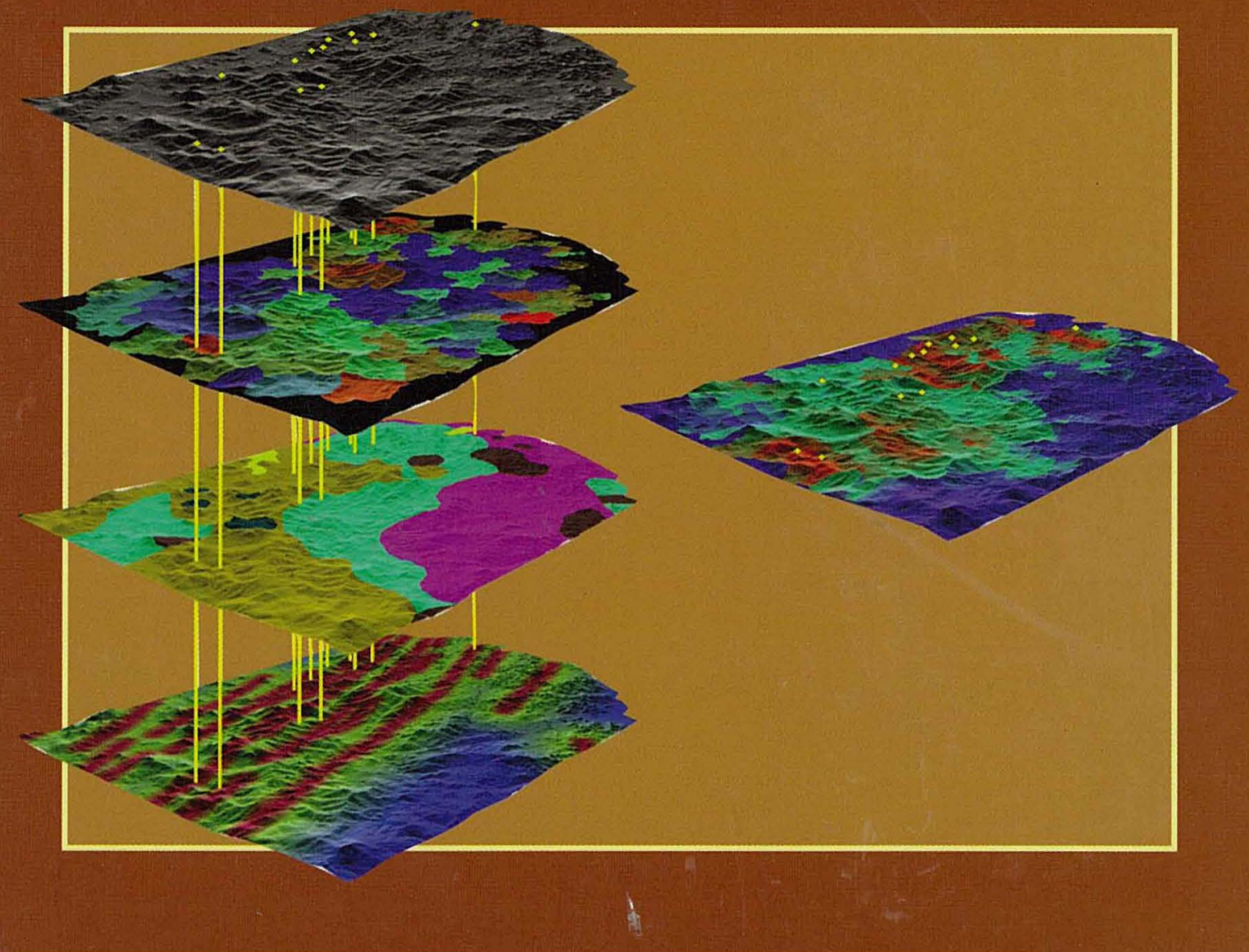


Handbook of Exploration and Environmental Geochemistry

VOLUME 11

Geochemical Anomaly and Mineral Prospectivity Mapping in GIS 


\section{HANDBOOK OF EXPLORATION GEOCHEMISTRY}

G.J.S. GOVETT (Editor)

1. ANALYTICAL METHODS IN GEOCHEMICAL PROSPECTING

2. STATISTICS AND DATA ANALYSIS IN GEOCHEMICAL PROSPECTING

3. ROCK GEOCHEMISTRY IN MINERAL EXPLORATION

4. REGOLITH EXPLORATION GEOCHEMISTRY IN TROPICAL AND SUB-TROPICAL TERRAINS

5. REGOLITH EXPLORATION GEOCHEMISTRY IN ARCTIC AND TEMPERATE TERRAINS

6. DRAINAGE GEOCHEMISTRY

7. GEOCHEMICAL REMOTE SENSING OF THE SUB-SURFACE

\section{HANDBOOK OF EXPLORATION AND ENVIRONMENTAL} GEOCHEMISTRY

\section{HALE (Editor)}

8. LIFE CYCLE OF THE PHOSPHORIA FORMATION - FROM DEPOSITION TO THE POST-MINING ENVIRONMENT

9. BIOGEOCHEMISTRY IN MINERAL EXPLORATION

10. THE INDIAN OCEAN NODULE FIELD

11. GEOCHEMICAL ANOMALY AND MINERAL PROSPECTIVITY MAPPING IN GIS 


\section{VOLUME 11 \\ Geochemical Anomaly and Mineral Prospectivity Mapping in GIS}

EMMANUEL JOHN M. CARRANZA

Department of Earth Systems Analysis

International Institute for Geo-Information Science and Earth Observation (ITC)

Enschede, The Netherlands

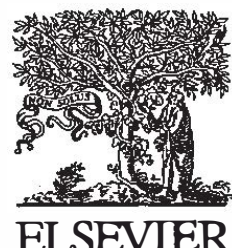




\section{Elsevier}

Radarweg 29, PO Box 211, 1000 AE Amsterdam, The Netherlands

Linacre House, Jordan Hill, Oxford OX2 8DP, UK

First edition 2009

Copyright @ 2009 Elsevier B.V. All rights reserved

No part of this publication may be reproduced, stored in a retrieval system or transmitted in any form or by any means electronic, mechanical, photocopying, recording or otherwise without the prior written permission of the publisher

Permissions may be sought directly from Elsevier's Science \& Technology Rights Department in Oxford, UK: phone (+44) (0) 1865 843830; fax (+44) (0) 1865 853333; email: permissions@elsevier.com. Alternatively you can submit your request online by visiting the Elsevier web site at http://elsevier.com/locate/permissions, and selecting Obtaining permission to use Elsevier material

Notice

No responsibility is assumed by the publisher for any injury and/or damage to persons or property as a matter of products liability, negligence or otherwise, or from any use or operation of any methods, products, instructions or ideas contained in the material herein.

\section{British Library Cataloguing in Publication Data}

A catalogue record for this book is available from the British Library

\section{Library of Congress Cataloging-in-Publication Data}

Carranza, Emmanuel John M. (Emmanuel John Muico, 1962-)

Geochemical anomaly and mineral prospectivity mapping in GIS / Emmanuel John M. Carranza. — 1 st ed.

p. cm. - (Handbook of exploration and environmental geochemistry ; vol. 11) ISBN 978-0-444-51325-0

1. Geochemistry-Remote sensing. 2. Mines and mineral resources-Remote sensing. 3. Geological mapping-Remote sensing. 4. Geographic information systems. I. Title.

QE515.5.R45C37 2009

$622^{\prime} .13-\mathrm{dc} 22$

ISBN: $\quad 978-0-444-51325-0$

For information on all Elsevier publications visit our website at books.elsevier.com

Printed and bound in Hungary

$\begin{array}{llllllllllllll}08 & 09 & 10 & 11 & 10 & 9 & 8 & 7 & 6 & 5 & 4 & 3 & 2 & 1\end{array}$

\section{Working together to grow libraries in developing countries} www.elsevier.com | www.bookaid.org | www.sabre.org 


\section{EDITOR'S FOREWORD}

In this volume John Carranza not only offers a comprehensive review of the current state-of-the-art of processing geochemical data, their integration with complementary geodata sets and multivariate data analysis using spatial statistics to create maps enhanced for mineral exploration, but also brings the Handbook series to something of a milestone. This marks the first volume in which the topic of an earlier volume (Vol. 2) is in effect revisited and updated; though the approach and format are - appropriately entirely fresh.

Part I of the volume (chapters 1-2) introduces the concepts and methods of handling spatial data in a geographical information system for the purpose of predictive modeling for mineral exploration. Part II (chapters 3-5) looks in detail at geochemical data and how they are analyzed, classified, synthesized and attributed to catchment basins prior to their application in predictive modeling. Part III (chapters 6-8) begins by emphasising the importance of additional relevant spatial information and culminates in predictive modeling of mineral prospectivity by means of a range of knowledge-driven and datadriven methods. Throughout the volume there is a wealth of well-illustrated real-world examples. The author admirably demonstrates modern approaches to data analysis and interpretation in mineral exploration in ways which exploration professionals can appreciate and adapt to their exploration programmes.

This volume is the first in the series to go to press after the death in 2007 of John S Webb, whose achievements and influence in exploration and environmental geochemistry did much to lay the foundations for the series. In the 1950s he established the Geochemical Prospecting Research Centre at Imperial College, London, where his pioneering work in exploration geochemistry was soon extended to regional geochemical mapping and environmental geochemistry (leading to the centre being renamed the Applied Geochemistry Research Group). Many destined later to be closely associated with the Handbook series were Webb's PhD students or colleagues at Imperial College: K Fletcher (Vol. 1); Richard Howarth (Vol. 2); Gerry Govett (Vol. 3, series founder and series editor Vols. 1-7); Charles Butt (Vol. 4); Martin Hale (Vols. 6-7 and series editor Vols. 8-11); and Colin Dunn (Vol. 9). In authoring Volume 11, John Carranza, being a former PhD student (and now professional colleague) of Martin Hale, has extended this tradition into the third generation.

Having in some ways brought the series full circle, Volume 11 also shows that geochemical data now constitute just one of several types of data brought together and analyzed together using geographical information systems to yield information to guide mineral exploration. The Handbook series has amply fulfilled Gerry Govett's original vision of thoroughly documenting the value of exploration and environmental 
geochemistry. Whilst the value of geochemical data remain undiminished in mineral exploration, John Carranza most eloquently shows here that the time has come when this value is best realized when geochemical data are part of wider armoury of complementary geodata sets and modeling techniques.

MARTIN HALE The Netherlands May 2008 


\section{PREFACE}

Twenty-five years ago, when the second volume of the Handbook of Exploration Geochemistry was published (Howarth, 1983), computers were just becoming useful tools in the analysis of mineral exploration data sets but mapping of geochemical anomalies and prospective areas still usually involved overlaying transparent geochemical map(s) and a geological map on a light table. The late 1980s through the 1990s saw rapid and far-reaching developments in quantitative techniques for mapping geochemical anomalies and mineral prospectivity due to the substantial improvements in the efficiency and availability of computer hardware and software (Agterberg, 1989) including geographic information system (GIS) technology (Burrough, 1987; BonhamCarter and Agterberg, 1990; Maguire et al., 1991). Two textbooks and several papers published in exploration-related literature have explained and documented various GISaided and/or GIS-based methods for analysis of multiple geoscience spatial data sets in order to derive and synthesise pieces of geo-information that are pertinent to the decision-making process at every scale of target generation in mineral exploration. In "Geographic Information Systems for Geoscientists: Modelling with GIS", BonhamCarter (1994) introduced ideas and methods of spatial analysis and modeling in GIS, especially those that are useful for characterising spatial associations between a set of geo-objects of interest (e.g., deposit-type locations) and individual sets of (indicative) spatial features (e.g., geochemical anomalies) in order to develop predictive models of the former set. In "Information Synthesis for Mineral Exploration", Pan and Harris (2000) introduced various methods for optimal assimilation of specific pieces of geoinformation extracted from various spatial data sets in order to derive optimised geoinformation for decision-making in mineral exploration. Nowadays, mapping of geochemical anomalies and/or prospective areas involves stacking digital geochemical and geological maps on top of each other on an electronic light table (i.e., in a GIS).

The objective of this book is to document, survey and demonstrate various GIS-aided and/or GIS-based techniques for mapping of geochemical anomalies and prospective areas during the target generation phase of mineral exploration. This volume consists of three parts, all centred on the theme predictive modeling or mapping and built upon particular notions and/or methods presented in the aforementioned textbooks and in various papers in exploration-related literature. Built upon the natural link between mapping of exploration targets and GIS, the chapters in Part I review and couple the concepts of (1) mapping geochemical anomalies and mineral prospectivity and (2) spatial data models, management and operations in a GIS. Built upon the remarks of Reimann (2005, pp. 369) that "Although GIS techniques appear to have simplified geochemical mapping tremendously, most systems do not allow for fast and correct class 
selection for mapping...", the chapters in Part II demonstrate GIS-aided and GIS-based methods for analysis of robust thresholds in mapping of geochemical anomalies. Built upon the notion that locations of mineral deposits of the type sought are intrinsic samples of mineralised landscapes, which are results of interactions of geological processes, the chapters in Part III explain GIS-aided and GIS-based techniques for spatial data analysis and geo-information synthesis for conceptual modeling and predictive modeling of mineral prospectivity. The essence of this book is, therefore, the prudent (thus, not black box) utilisation of GIS in mapping of geochemical anomalies and prospective areas through the application of understanding of relevant earth systems or processes that led to the formation (and/or alteration) of these geo-objects.

Each chapter in this volume is meant to be self-contained. The chapters in Parts II and III are, however, coherently linked by a common case study. The concepts and methods described here are demonstrated with real exploration data sets. Although the geochemical data used here represent Earth materials most commonly sampled in reconnaissance exploration surveys (i.e., stream sediments) and the geological data sets used here represent 'data-poor' situations of mapping exploration targets for epithermal Au deposits, the concepts and methods described here apply equally to geochemical data from different sampling media and to 'data-rich' situations of mapping exploration targets for various types of mineral deposits. In addition, whilst there is neither reference to nor endorsement of any GIS software throughout this volume, the concepts and methods described in every chapter are generic such that they are readily implemented with or in any GIS software. This volume is thus intended to be an instructional textbook and general reference manual for exploration geochemists and/or exploration geologists, who are enthusiastic and already possess skills in applying GIS or who are interested in applying GIS. It is also hoped that geoscience academics and graduate students not only in the knowledge fields of geo-resource exploration but also in the knowledge fields of geo-hazard mapping and/or geo-environmental characterisation would find the concepts and methods described in this volume useful in their work.

I thank the Intermational Institute for Geo-Information Science and Earth Observation (ITC) for resources and a pleasant environment for working (both teaching and doing research in geological predictive modeling) that allowed me to write this book. I thank also my graduate (PhD/MSc) students, from 2002 to the present, with whom I have developed some of the ideas presented in this volume. Most of all, I thank Professor Martin Hale, for coaching me during the years I was a graduate (MSc to PhD) student of mineral exploration at ITC and TU Delft, for continuing to work with me thereafter, for inviting me to write a volume for the series of Handbook of Exploration and Environmental Geochemistry and for editing this volume. The errors in this volume remain mine.

E.J.M. CARRANZA

Enschede, The Netherlands

May 2008 


\section{CONTENTS}

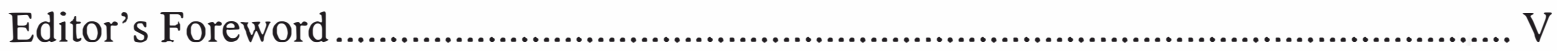

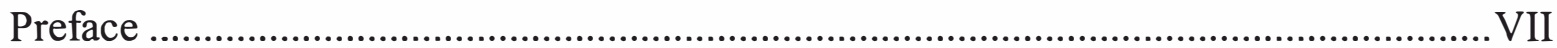

\section{PART I. MODELS IN MINERAL EXPLORATION AND GIS}

Chapter 1. Predictive Modeling of Mineral Exploration Targets ..................................... 3

Introduction ................................................................................................... 3

What is Predictive Modeling?........................................................................... 4

Approaches to predictive modeling ……………………................................. 5

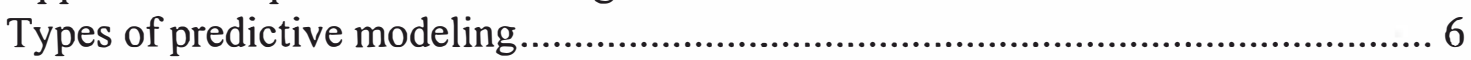

Predictive Modeling of Significant Geochemical Anomalies ...................................... 9

Predictive Modeling of Mineral Prospectivity ........................................................ 12

Predictive Modeling with a GIS......................................................................... 18

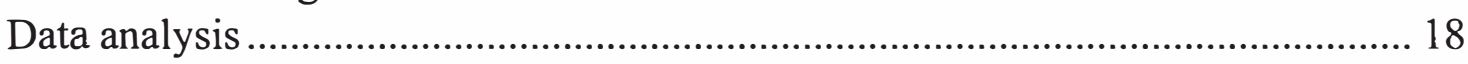

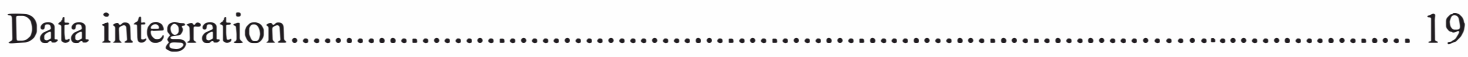

Visualisation of spatial data or geo-information ................................................ 20

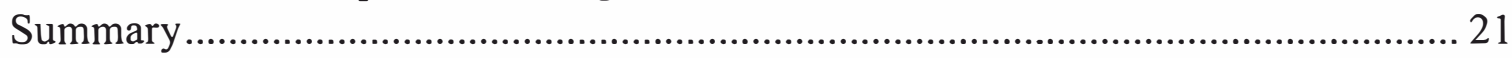

Chapter 2. Spatial Data Models, Management and Operations .................................... 23

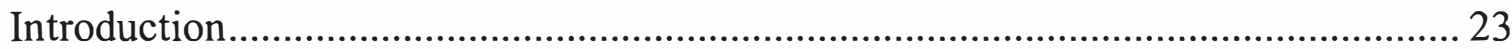

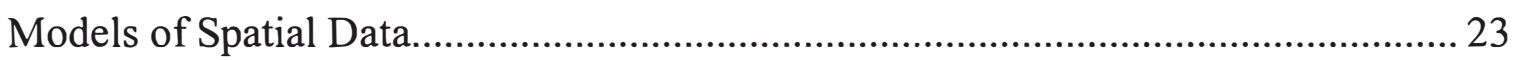

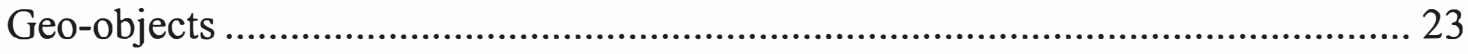

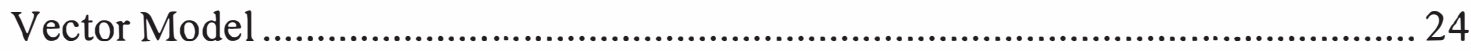

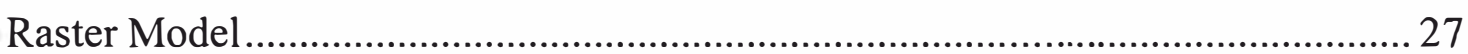

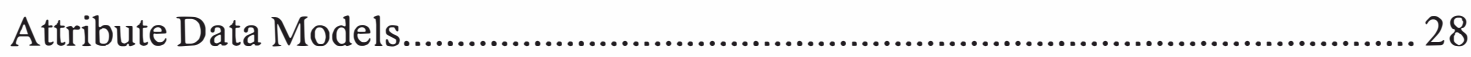

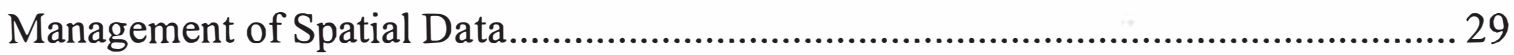

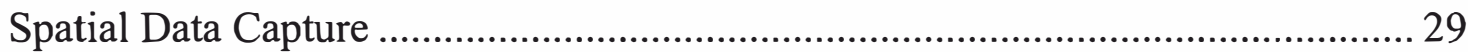

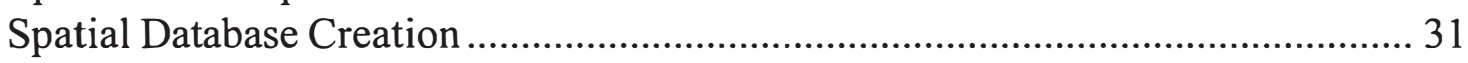

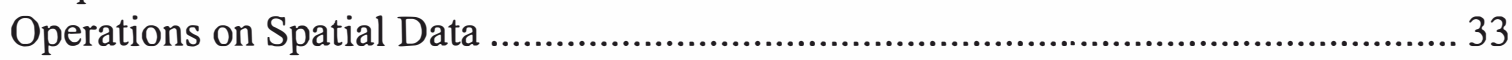

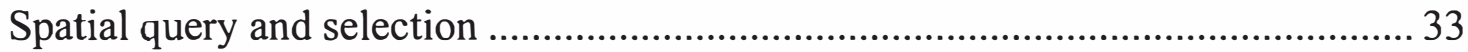

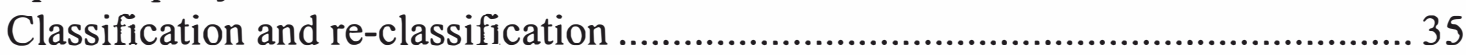

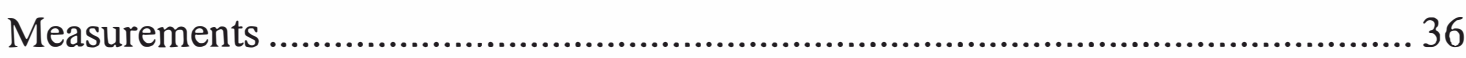

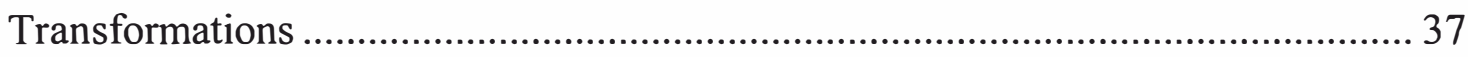

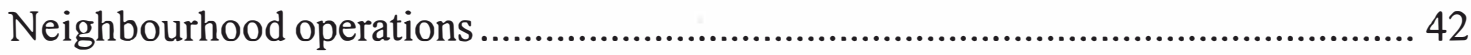

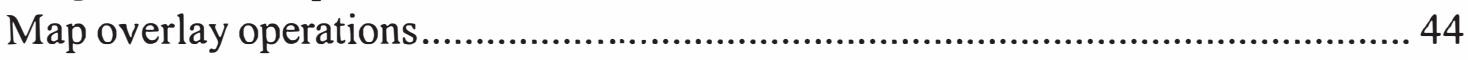

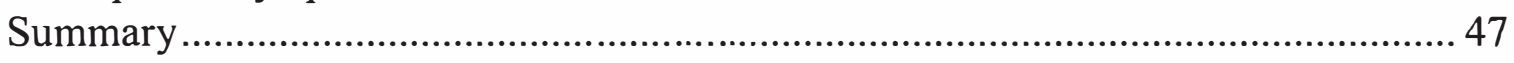




\section{PART II. GEOCHEMICAL ANOMALY MAPPING}

Chapter 3. Exploratory Analysis of Geochemical Anomalies ....................................... 51

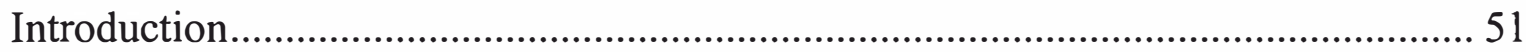

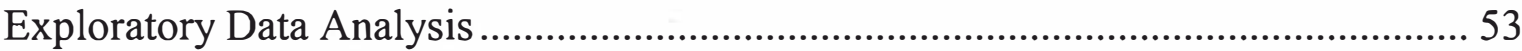

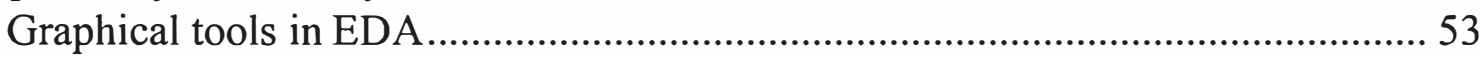

Boxplot and 5-number statistics of univariate data................................................ 54

Classification of uni-element geochemical data...................................................... 57

Standardisation of classified uni-element geochemical data ..................................... 57

Mapping of classified uni-element geochemical data ............................................... 59

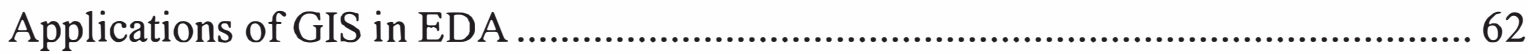

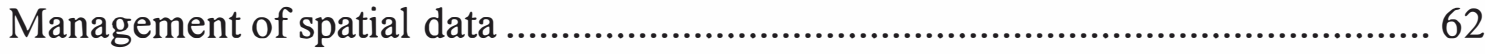

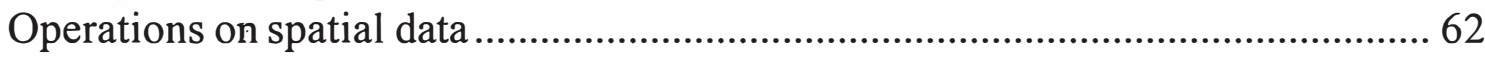

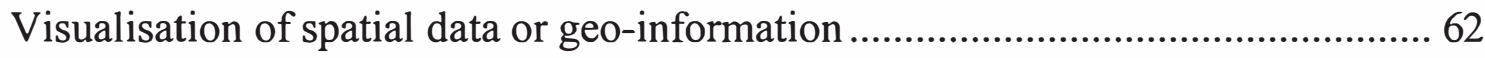

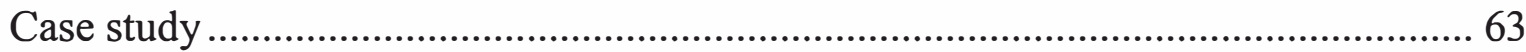

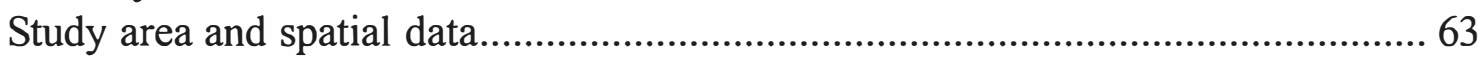

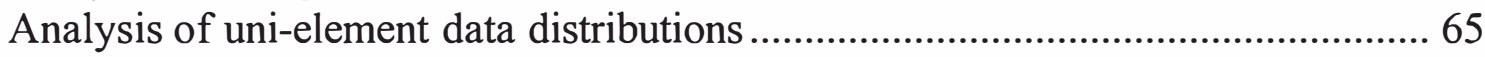

Analysis of uni-element threshold values and anomalies....................................... 72

Analysis of inter-element relationships............................................................... 75

Analysis and mapping of multi-element associations ............................................. 78

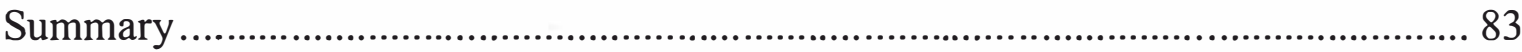

Chapter 4. Fractal Analysis of Geochemical Anomalies ............................................. 85

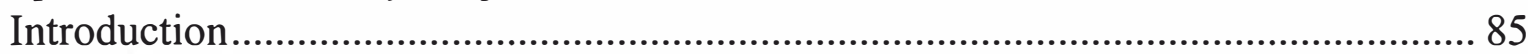

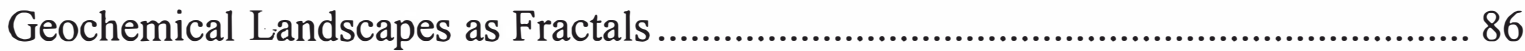

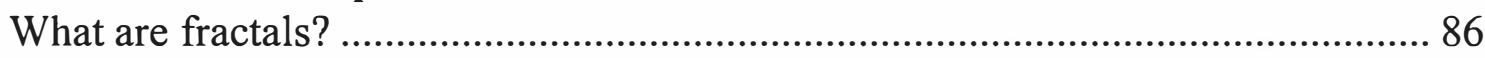

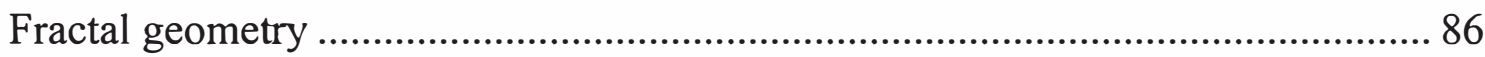

Perimeter-area relationship in geochemical patterns............................................ 88

Multifractality of geochemical landscapes........................................................... 92

The Concentration-Area Method for Threshold Recognition ...................................... 92

Application of GIS in the Concentration-Area Fractal Method .................................... 94

Generation and discretisation of geochemical surfaces ......................................... 95

Attribute table operation for area calculations ...................................................... 96

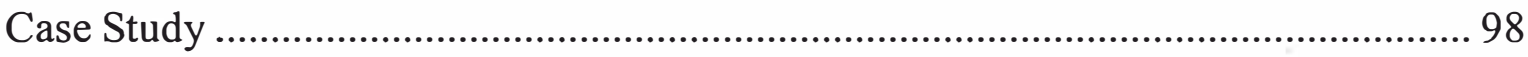

Creation and classification of uni-element geochemical surface maps.................... 98

Analysis of uni-element threshold values and anomalies...................................... 100

Analysis and mapping of anomalous multi-element signature............................... 107

Synthesis of multi-element associations .......................................................... 110

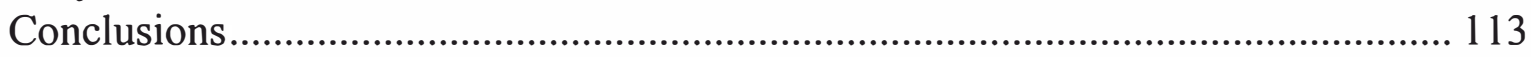


Chapter 5. Catchment Basin Analysis of Stream Sediment Anomalies ....................... 115

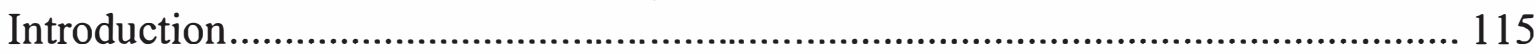

Estimation of Local Uni-element Background due to Lithology ........................... 117

Multiple regression analysis.............................................................. 117

Analysis of weighted mean uni-element concentrations due to lithology ............ 118

Dilution Correction of Uni-element Residuals................................................. 120

Analysis of Anomalous Multi-element Signatures ............................................. 122

Application of GIS in Catchment Basin Analysis ............................................. 125

Creation of sample catchment basins .......................................................... 125

Measuring areas and areal proportions of lithologic units in catchment basins .... 127

Estimation of local background uni-element concentrations ........................... 127

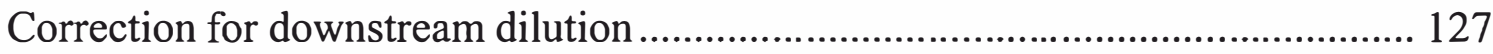

Analysis and classification of geochemical anomalies .................................... 128

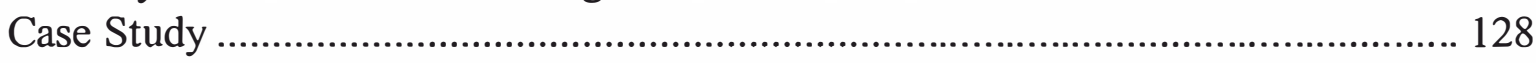

Estimation of local uni-element background ............................................ 129

Derivation and standardisation of uni-element residuals ............................... 133

Correction for downstream dilution and classification of anomalies .................... 136

Modeling of multi-element anomalies via principal components analysis .......... 136

Screening of multi-element anomalies with fault/fracture density .................... 141

Discussion and Conclusions .......................................................................... 142

\section{PART III. MINERAL PROSPECTIVITY MAPPING}

Chapter 6. Analysis of Geologic Controls on Mineral Occurrence ............................ 147

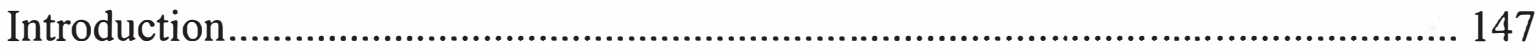

Spatial Distribution of Mineral Deposits ....................................................... 148

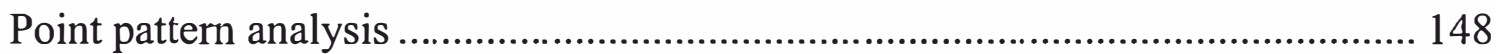

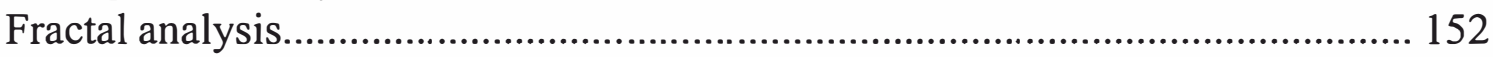

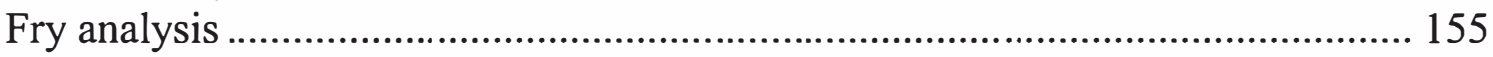

Knowledge synthesis and results of spatial analysis ..................................... 158

Spatial Association of Mineral Deposits and Geologic Features ............................. 162

Distance distribution method ..................................................................... 162

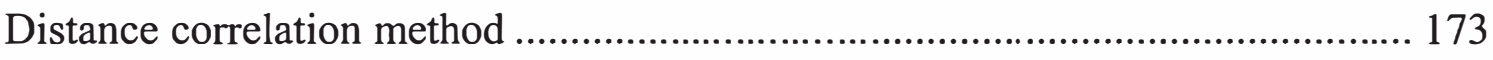

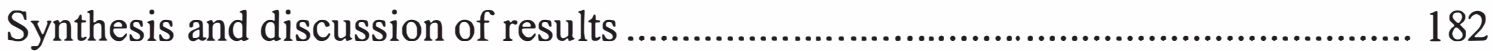

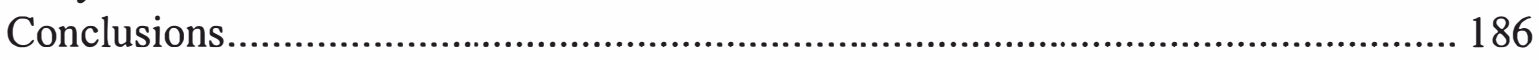

Chapter 7. Knowledge-Driven Modeling of Mineral Prospectivity ............................ 189

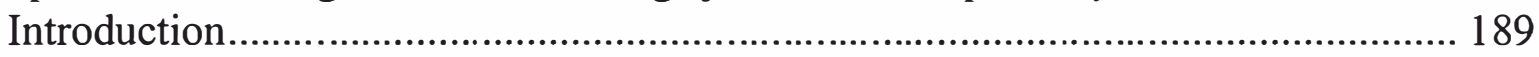

General Purpose Applications of GIS ......................................................... 191

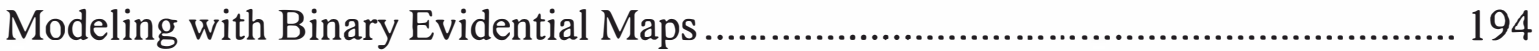

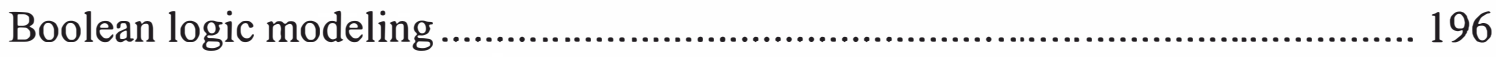

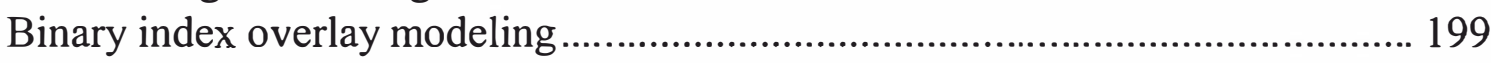


Calibration of predictive modeling with binary evidential maps ....................... 204

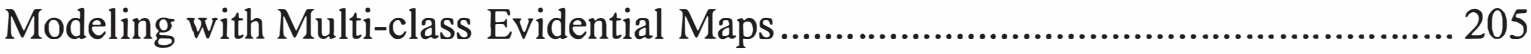

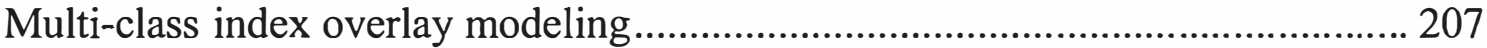

Fuzzy logic modeling ...................................................................... 210

Evidential belief modeling ................................................................. 227

Calibration of predictive modeling with multi-class evidential maps ................. 235

Wildcat Modeling of Mineral Prospectivity..................................................... 236

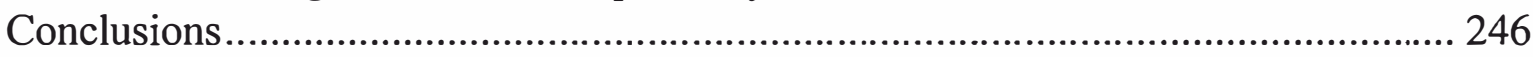

Chapter 8. Data-Driven Modeling of Mineral Prospectivity ...................................... 249

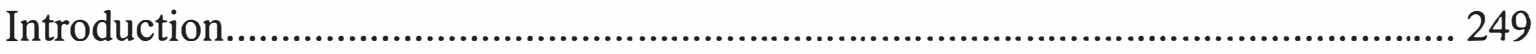

Selection of Suitable Unit Cell Size for Modeling ................................................ 253

Selection of Coherent Deposit-type Locations for Modeling................................. 260

Analysis of mineral occurrence favourability scores at deposit-type locations .... 261

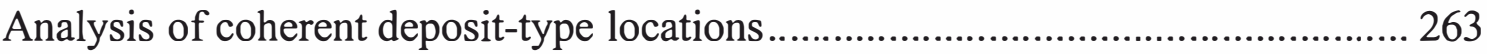

Cross-validation of Data-driven Models of Prospectivity...................................... 270

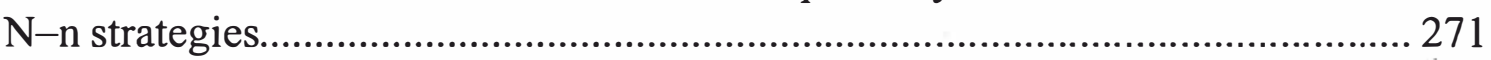

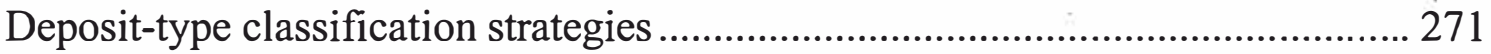

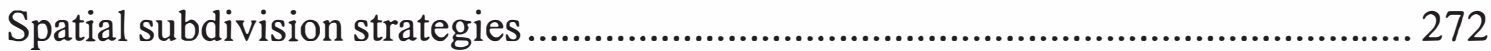

Other strategies of cross-validation................................................................ 272

Evidential Belief Modeling of Mineral Prospectivity ........................................... 273

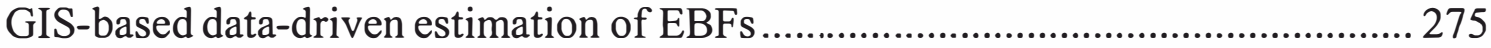

Calibration of data-driven estimation of EBFs ........................................... 279

Integration of data-driven EBFs .......................................................... 285

Case study application of data-driven EBFs .................................................. 286

Discriminant Analysis of Mineral Prospectivity ................................................. 293

Basic principles and assumptions of linear discriminant analysis....................... 293

GIS-based spatial evidence representation for discriminant analysis .................. 295

Case study application of discriminant analysis........................................ 295

Discussion and Conclusions....................................................................... 308

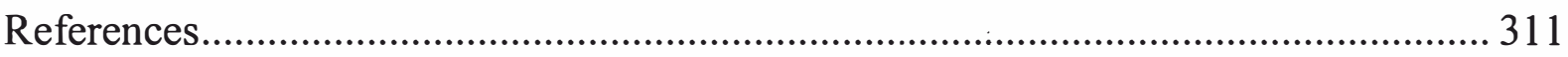

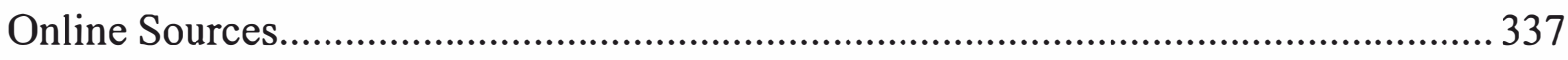

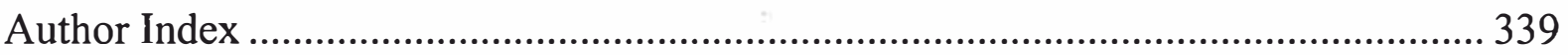

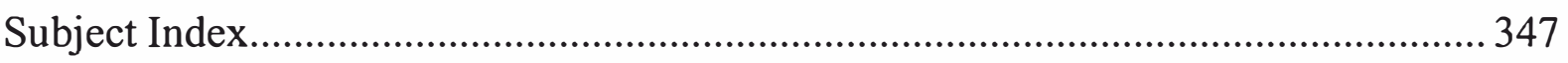

